American Journal of Applied Sciences 5 (9): 1141-1143, 2008

ISSN 1546-9239

(C) 2008 Science Publications

\title{
Effect of Film thickness on the Electrical and Structural Properties of CdS: In Thin Films
}

\author{
${ }^{1}$ Shadia J. Ikhmayies, ${ }^{2}$ Riyad N. Ahmad-Bitar \\ ${ }^{1}$ Department of Physics, Faculty of Basic Science, Applied Science Private \\ University, Amman, Jordan. \\ ${ }^{2}$ Department of Physics, Faculty of Science, University of Jordan, Amman, Jordan
}

\begin{abstract}
Polycrystalline CdS:In thin films were prepared by the Spray Pyrolysis (SP) technique on glass substrates at a substrate temperature $\mathrm{T}_{\mathrm{s}}=490^{\circ} \mathrm{C}$. The effect of film thickness on the electrical and structural properties of the films was investigated through the analysis of the I-V plots, $x$-ray diffraction spectra (XRD) and the scanning electron microscope (SEM) images. The conductivity of the films was highly increased when the films became thicker. The crystal growth became stronger and more oriented as seen in the x-ray diffraction spectra and the grain size became larger as seen in the SEM images.
\end{abstract}

Key words: CdS:In; thin films, solar cells, doping

\section{INTRODUCTION}

Thin films of CdS have been extensively studied due to the variety of applications in optoelectronic devices. In particular heterojunction solar cells with a narrow bandgap base and a wide bandgap window ${ }^{[1]}$ such as $\mathrm{CdS} / \mathrm{CdTe}$ and $\mathrm{CdS} / \mathrm{CuInSe}$ solar cells.

There are several methods for depositing CdS thin films, such as; vacuum evaporation (VE) ${ }^{[2]}$, chemical bath deposition $(\mathrm{CBD})^{[1,3,4]}$, spray pyrolysis $(\mathrm{SP})^{[5,6]}$, etc. However, the SP technique is a very low cost and simple technique that enables intentional doping and getting large area and uniform thin films ${ }^{[5,6]}$.

In this study polycrystalline CdS:In thin films were prepared by the SP technique at a substrate temperature $\mathrm{T}_{\mathrm{s}}=490^{\circ} \mathrm{C}$. The effects of film thickness on the electrical and structural properties of CdS:In thin films were investigated through the analysis of the I-V plots, the XRD spectra and the SEM images.

\section{MATERIALS AND METHOD}

The precursor solution of the spray-deposited CdS thin films was prepared by dissolving $2.06 \times 10^{-2}$ moles of extra pure $\mathrm{CdCl}_{2} \cdot \mathrm{H}_{2} \mathrm{O}$ (MERECK Art. 2011) and $2.24 \times 10^{-2}$ moles of thiourea $\left(\mathrm{NH}_{2}\right)_{2} \mathrm{CS}(>97 \% \mathrm{~S})$ in 350 $\mathrm{ml}$ of distilled water. Indium chloride $\mathrm{InCl}_{3}$ (MERECK Art.12471) was used as a doping compound. The ratio of the concentration of indium ions to that of cadmium ions in the solution $\left(\left[\mathrm{In}^{+3}\right] /\left[\mathrm{Cd}^{+2}\right]\right)$ which is not necessarily the same as their ratio in the films was used as an indication of the doping ratio. The solution was sprayed intermittently by using the spraying system described in ${ }^{[5]}$ on glass substrates that were ultrasonically cleaned with methanol at a substrate temperature $\mathrm{T}_{\mathrm{s}}=490^{\circ} \mathrm{C}$.

The films' thickness was in the range 100-1000 nm. It was estimated by using Lambert law for absorption in a semiconductor. That is by making use of the relative transmittance through each film at a certain wavelength which was measured by a double beam Shimadzu UV 1601 (PC) spectrophotometer.

The contacts are two strips of $\mathrm{Ag}$ or $\mathrm{Al}$ made on the surface of the film by vacuum evaporation. They are $1 \mathrm{~cm}$ in length, $1 \mathrm{~mm}$ in width, $0.4 \mu \mathrm{m}$ in thickness and separated by $2-3 \mathrm{~mm}$. The I-V measurements were taken by using a Keithley 2400 Source Meter, which was interfaced by an IBM personal computer. The samples were placed in a brass cell that had a cover to enable measurements in the dark. The sample in question was placed in the brass cell mentioned before.

XRD measurements were made with a Philips PW1840 Compact X-ray diffractometer system with $\mathrm{Cu}$ $\mathrm{K}_{\alpha}(\lambda=1.5405 \AA)$. The diffraction angle $2 \theta$ was varied from $2^{\circ}$ to $60^{\circ}$, and the peaks in the obtained diffraction spectra were identified. The SEM images of the CdS:In

Corresponding Author: Shadia J. Ikhmayies, Department of Physics, Faculty of Basic Science, Applied Science Private University, Amman, Jordan. Tel: (00962-6) 5609999-1113; Fax: (00962) 5232899 
thin films were taken by a LEITZ-AMR 1000A scanning electron microscope. The film was covered with a sputtered gold layer $(\sim 20 \mathrm{~nm})$ before taking the measurements. The purpose of this layer was to prevent sample charging effects.

\section{RESULTS AND DISCUSION}

Electrical properties: The I-V curves which are all linear were recorded at room temperature in the dark. The slope was used to determine the resistance of each film and then its conductivity. Figure 1. a shows one of these plots for two CdS:In thin films of doping ratio $1 \times 10^{-4}$ and different film thickness. The film of thickness $\mathrm{t}=100 \quad \mathrm{~nm} \quad$ has a conductivity $\sigma=1.18 \times 10^{-8} \Omega^{-1} \cdot \mathrm{cm}^{-1}$, while the conductivity of the film of thickness $t=300 \mathrm{~nm}$

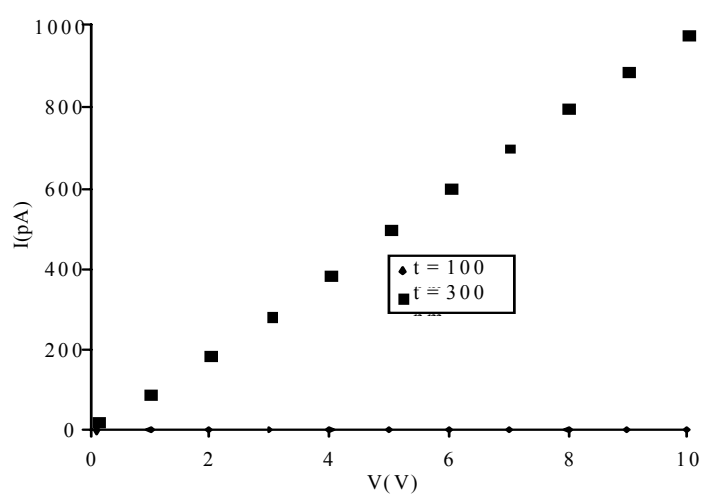

a

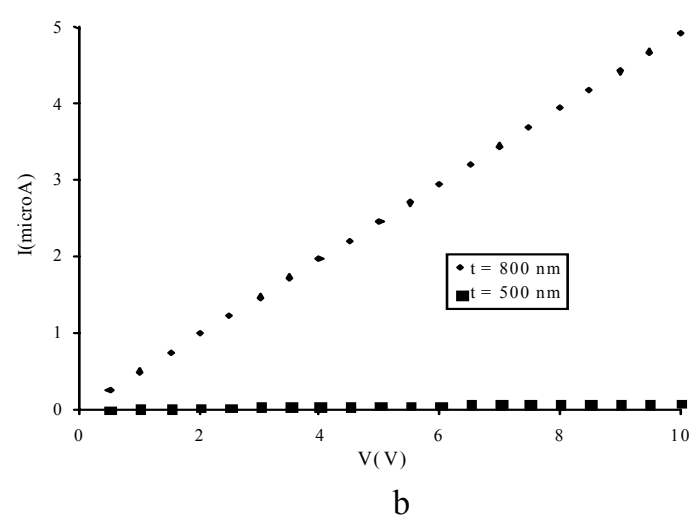

Fig.1: I-V plots for CdS:In thin films of different thickness. a) The films have a doping ratio $=1 \times 10^{-4}$ and $\mathrm{Ag}$ contacts. b) The films have a doping ratio $=1.5 \times 10^{-2}$ and $\mathrm{Al}$ contacts is $8.33 \times 10^{-7} \Omega^{-1} \cdot \mathrm{cm}^{-1}$. That is the conductivity was increased by a factor of about 71 . Figure $1 \mathrm{~b}$ displays the I-V curves for two films of doping ratio $1.5 \times 10^{-2}$ with different thickness. The conductivity of the film of thickness $\mathrm{t}=500 \mathrm{~nm}$ is $5.0 \times 10^{-5} \Omega^{-1} . \mathrm{cm}^{-1}$ and that of the film of thickness $\mathrm{t}=800 \mathrm{~nm}$ is $1.11 \times 10^{-3} \Omega^{-1} \cdot \mathrm{cm}^{-1}$, or it is increased by a factor of about 22 . This increase in the conductivity with film thickness can be explained by the increase in grain size and the enforcement of crystal growth as seen in the following XRD spectra and the SEM images.

XRD spectra: The thickness had a pronounced effect on the X-ray diffraction spectra of the CdS:In thin films as shown in Fig. 2. A comparison between the spectra of the two films in (a) and (b) shows that there is more crystallization and more orientation of the crystal growth in the case of the thicker film. The lines H(101) and $\mathrm{C}(311) / \mathrm{H}(112)$ became more stronger than the other lines and have comparable intensities with a slight preferential orientation in the $\mathrm{C}(311) / \mathrm{H}(112)$ direction.

SEM Images: Fig. 3. Shows the SEM images for two $\mathrm{CdS}$ : In thin films with the same doping ratio $1 \times 10^{-4}$ and different thickness. As the figure shows, the grain size was greater in the thicker film. Chow et $\mathrm{al}^{[7]}$ had recorded an increase in the grain size with film thickness. For their spray deposited CdS films they found an increase in the crystal grain size with increasing the sprayed solution up to about $2000 \mathrm{~mL}$ (or

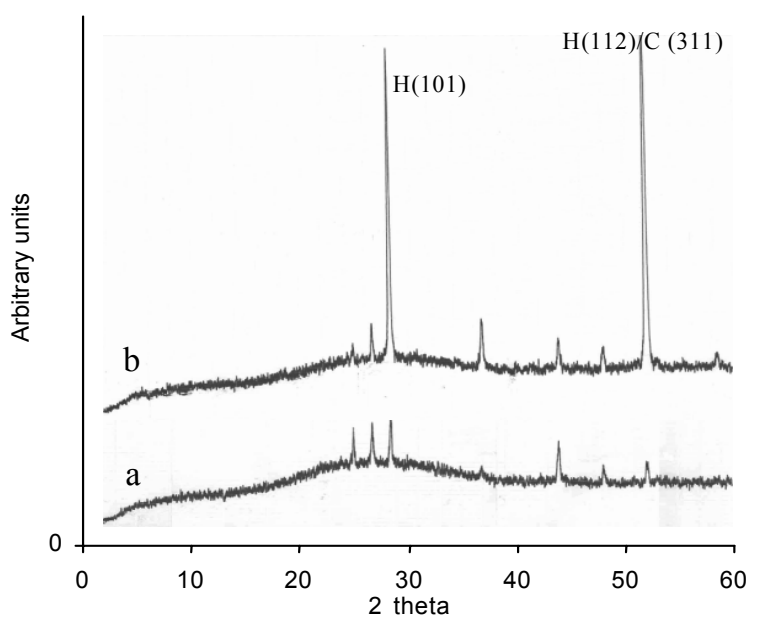

Fig. 2: X-ray diffraction spectra for CdS:In thin films of doping ratio $=1 \times 10^{-4} \quad$ deposited at $\mathrm{T}_{\mathrm{s}}=$ $490^{\circ} \mathrm{C}$. (a) $\mathrm{t}=140 \mathrm{~nm}$. (b) $\mathrm{t}=500 \mathrm{~nm}$ 


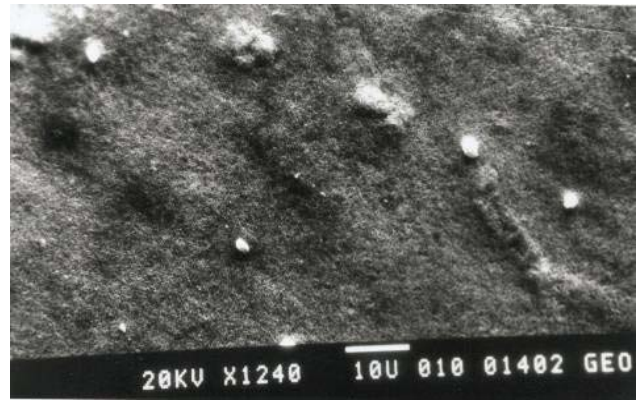

a

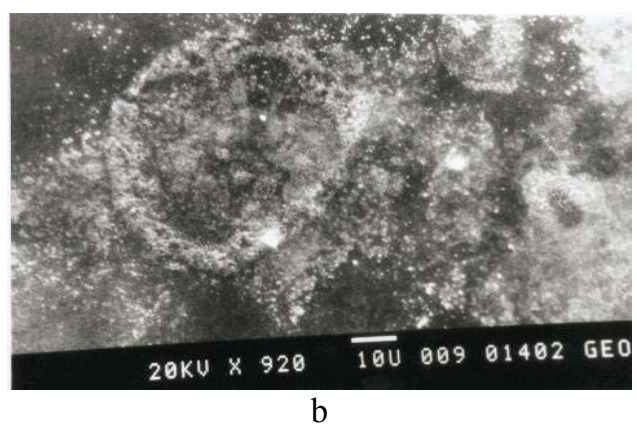

Fig. 3: SEM images for CdS:In thin films of doping ratio $=1 \times 10^{-4}$. a) $\mathrm{t}=100 \mathrm{~nm}$. b) $\mathrm{t}=500 \mathrm{~nm}$.

a film thickness of $4 \mu \mathrm{m}$ ). Beyond that value the grain size saturated. Also Kwok and $\mathrm{Siu}^{[8]}$ found that for Idoped CdS films, the grain size was less than $1 \mu \mathrm{m}$ for thin films $(<2 \mu \mathrm{m})$ and $1-4 \mu \mathrm{m}$ for thick films $(>2 \mu \mathrm{m})$.

\section{CONCLUSIONS}

The effect of film thickness on the electrical and structural properties of the films was investigated through the analysis of the I-V plots, XRD spectra and SEM images. It was found that the conductivity increases with film thickness. This improvement in the conductivity is due to the enhancement of the crystal growth as seen in the XRD spectra and then the increase in the grain size as seen in the SEM images.

\section{ACKNOWLEDEMENT}

We want to thank Sameer Farrash in the University of Jordan for making the contacts by vacuum evaporation, Khalil Tadros in the university of JordanGeology department for the SEM images, and Marsil Imsais for the XRD spectra in the university of JordanGeology department too.

This paper received financial support towards the cost of its publication from the Deanship of Research and Graduate Studies at Applied Science University, Amman - Jordan.

\section{REFERENCES}

1. Ariza-Calderon, H., R. Lozada-Morales, O. ZelayaAngel, G.J. Mendoza- Alvarez and L. Baños, 1996. Photoluminescence measurements in the phase transition region for $\mathrm{CdS}$ thin films. J. Vac. Sci. Technol. A, 14 (4): 2480-2482.

2. Lepek M., and B. Dogil 1983. A study of CdS thin film deposition. Thin Solid Films, 109: L103-L107.

3. Melo de, O., L. Hernández O. Zelaya-Angel, R. Lozada-Morales, M. Becerril and E. Vasco, 1994. Low resistivity cubic phase CdS films by chemical bath deposition technique. Appl. Phys. Lett. 65 (10): 1278-1280.

4. Vigil, O., I. Riech, M. Garcia-Rocha and O. J. Zelaya-Angle, 1997. Characterization of defect levels in chemically deposited $\mathrm{CdS}$ films in the cubic-to hexagonal phase transition. Vac. Sci. Technol. A 15 (4): 2282-2286.

5. Ikhmayies. J. Shadia., 2002. Production and characterization of $\mathrm{CdS} / \mathrm{CdTe}$ thin film photovoltaic solar cells of potential industrial use. Ph.D. Thesis. University of Jordan, Amman, Jordan,

6. Slawh G. G., Z .W. Manookian and S.A.W. Abdul Ghafor, 1991. Optical and electrical properties of CdS thin films prepared by spraying pyrolysis technique. Iraqi Soc. Phys. and Math., J. Math. Phys. 12 (1): 91-98.

7. Chow, W. L., C. Y. Lee and L. H. Kwok, 1981. Structure and electronic properties of chemically sprayed CdS films. Thin Solid Films. 81: 307-318.

8. Kwok, H.L., and W.C. Siu 1979. Carrier concentration and mobility in chemically sprayed cadmium sulfide thin films. Thin Solid Films,61: 249-257. 